Research Article

\title{
Examination of Environmental Factors Influencing the Emission Rates of Semivolatile Organic Compounds
}

\author{
Sunwoo Lee ${ }^{1}$ and Janghoo Seo $\mathbb{D}^{2}$ \\ ${ }^{1}$ Zero-Energy Appropriate Technology Institute, Seoul Energy Dream Center, 14 Jeungsan-ro, Mapo-gu, Seoul 03901, \\ Republic of Korea \\ ${ }^{2}$ School of Architecture, Kookmin University, 77 Jeongneung-ro, Seongbuk-gu, Seoul 02707, Republic of Korea \\ Correspondence should be addressed to Janghoo Seo; seojh@kookmin.ac.kr
}

Received 13 December 2017; Accepted 18 January 2018; Published 15 March 2018

Academic Editor: Geun Y. Yun

Copyright (C) 2018 Sunwoo Lee and Janghoo Seo. This is an open access article distributed under the Creative Commons Attribution License, which permits unrestricted use, distribution, and reproduction in any medium, provided the original work is properly cited.

\begin{abstract}
Some types of semivolatile organic compounds (SVOCs) that are emitted from plastics used in building materials and household appliances have been associated with health risks, even at low concentrations. It has been reported that di-2-ethylhexyl phthalate (DEHP) - one of the most commonly used plasticizers - causes asthma and allergic symptoms in children at home. The amount of emitted DEHP, which is classified as a SVOC, can be measured using a microchamber by the thermal desorption test chamber method. To accurately measure the SVOC emission rates, the relation between SVOC and environmental factors should be clarified. Herein, we examined the effects of the temperature, relative humidity, concentration of airborne particles, and flow field in the microchamber on SVOC emission rates. The flow fields inside the microchamber were analyzed via computational fluid dynamics (CFD). The emission rate of SVOC released from PVC flooring increased under high temperatures and at high concentrations of airborne particles but did not depend on the relative humidity. From an evaluation performed using an index of air change efficiency, such as the air age and the coefficient of air change performance, we found that a fixed air exchange rate of $1.5 \mathrm{~h}^{-1}$ in the microchamber is desirable.
\end{abstract}

\section{Introduction}

Semivolatile organic compounds (SVOCs) are used as plasticizers in building materials, interior materials, furniture, and consumer electronics. At home, these SVOCs mix with house dust. Therefore, there is a concern over the health effects of SVOCs because there is a risk that they may cause asthma and allergic symptoms in children at home [1-15].

The thermal desorption test chamber (TDC) method was developed in Japan. This technique can be employed to determine the emission rates of SVOCs under room-temperature conditions using a microchamber [16-19]. Additionally, a TDCbased microchamber method approach was standardized as JIS A 1904 as a method for determining the emission of SVOCs from building materials [20].

We verified the accuracy of the measurements using a microchamber and the TDC method as well as the reproducibility of the microchamber method. They determined the emission rate of SVOCs from various types of materials and investigated the recovery ratios of the microchamber using reference materials $[18,21]$. Next, they selected a number of factors, including background concentration, loading factor, specimen orientation, time, type of gas supplied, and process effects on the inner surface of the microchamber, which were expected to affect the emission behavior of SVOCs with the microchamber method and reported the results [21, 22]. Meanwhile, the temperature, relative humidity, air exchange rate, and other factors have been considered to affect the emission rate of chemicals using JIS A 1901 and other general test chamber methods [23]. Although it may be predicted that the aforementioned factors can also influence the measurement of SVOC emission rates using the microchamber method, there are a few investigated cases. Moreover, SVOCs have an extremely low volatility and are easily adsorbed to the surfaces of solids. To investigate the factors that influence the emission rate of SVOCs, it is essential to investigate the 


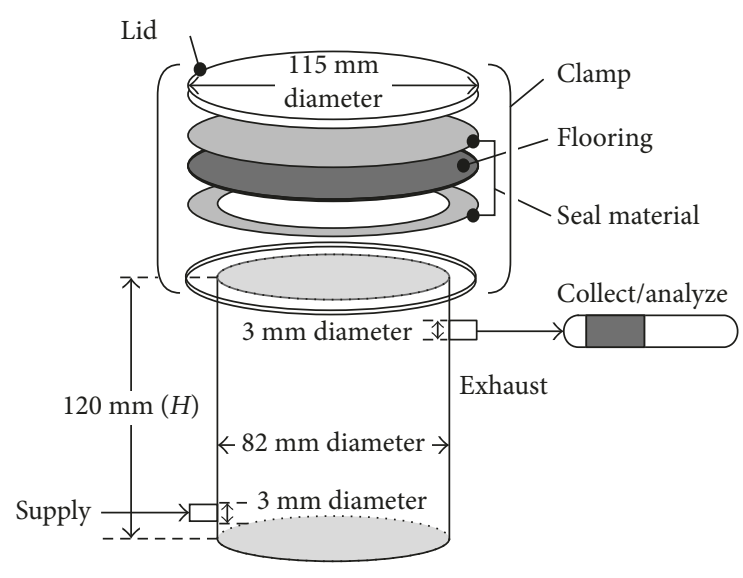

Figure 1: Schematic of the microchamber.

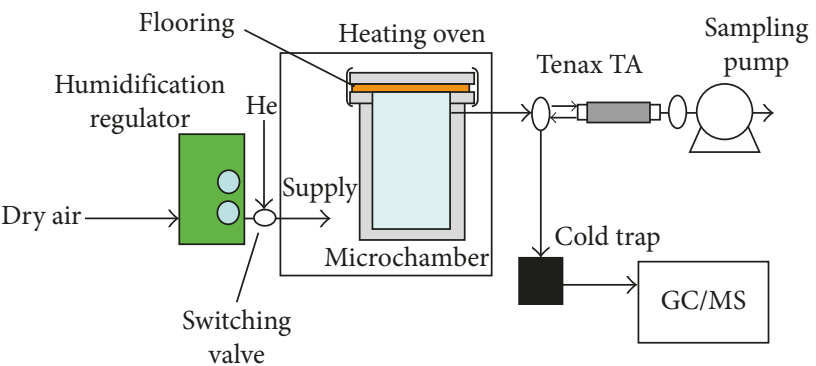

Figure 2: Schematic of the thermal desorption test chamber system.

correlation between the SVOC emission rate and airborne particles in the room. Herein, we study the dependence of the emission rate of di-2-ethylhexyl phthalate (DEHP) - an SVOC-on the temperature, relative humidity, and airborne particles. Additionally, we investigated the influence of varying the air exchange rate properties of the microchamber on its flow field using computational fluid dynamics (CFD).

\section{Method}

2.1. Microchamber System. Figure 1 shows a schematic of the microchamber, which is made of glass and has been treated with silane. The microchamber is cylindrical $(82 \mathrm{~mm}$ (diameter) $\times 120 \mathrm{~mm}$ (height) $)$. Air enters the microchamber through an inlet (inner diameter $=3 \mathrm{~mm}$ ) at the lower side of the cylinder (13 $\mathrm{mm}$ from the bottom). Directly opposite to this inlet, on the upper side of the cylinder $(96 \mathrm{~mm}$ from the bottom), there is a collection outlet (inner diameter $=3 \mathrm{~mm}$ ). On top of the microchamber, there is a $15 \mathrm{~mm}$ rim on which a glass lid (diameter $=11.5 \mathrm{~mm}$ ) is placed. A clamp is used to hold a seal and a flooring material in place while keeping the interior of the microchamber airtight. The emission area of the building material is $5.3 \times 10^{3} \mathrm{~mm}^{2}$.

Figure 2 shows a schematic of the thermal desorption test chamber system. SVOCs are easily adsorbed by the microchamber walls under room-temperature conditions. The thermal desorption test chamber method measures emissions based on the adsorbed constituents. After collecting
TABle 1: Measurement conditions of the thermal desorption test chamber system.

\begin{tabular}{lc}
\hline \multicolumn{2}{c}{ SVOC constituent adsorption process } \\
\hline Gas supply & Air \\
Temperature and humidity & $28^{\circ} \mathrm{C}$ and $50 \% \mathrm{RH}$ \\
Air exchange rate & $1.5 \mathrm{~h}^{-1}$ \\
Loading factor & $8.4 \mathrm{~m}^{2} / \mathrm{m}^{3}$ \\
Sampling rate & $23 \mathrm{~L}\left(16 \mathrm{ml} / \mathrm{min}^{2} 24 \mathrm{~h}\right)$ \\
Scavenger & Tenax TA $(60 / 80)$ \\
\hline \multicolumn{1}{c}{ SVOC constituent thermal desorption process } \\
\hline Gas supply & Helium $(90 \mathrm{ml} / \mathrm{min})$ \\
Air exchange rate & $4.6 \mathrm{~h}^{-1}$ \\
Sampling rate & $75 \mathrm{~min} / 3.75 \mathrm{~L}$ \\
Temperature of the thermal & $28^{\circ} \mathrm{C}(30 \mathrm{~min}) \rightarrow$ \\
desorption system & $15^{\circ} \mathrm{C} / \mathrm{min} \rightarrow 200^{\circ} \mathrm{C}(30 \mathrm{~min})$ \\
Scavenger & Tenax TA $(60 / 80)$
\end{tabular}

TABle 2: Analytical conditions of the gas chromatography/mass spectrometry thermal desorption system (GC/MS-TDS).

\begin{tabular}{lc}
\hline GC/MS & Agilent HP6890-G1530A/HP5973MSD \\
Column & TC5 $0.25 \mu \mathrm{m} \times 0.25 \mathrm{~mm}(\mathrm{I} . \mathrm{D}.) \times 30 \mathrm{~m}$ \\
Oven & $(\mathrm{GL}$ science $)$ \\
temperature & $40^{\circ} \mathrm{C}(2 \mathrm{~min}) \rightarrow 15^{\circ} \mathrm{C} / \mathrm{min} \rightarrow 270^{\circ} \mathrm{C}(21 \mathrm{~min})$ \\
Split ratio & $50: 1$ \\
CIS & $-130^{\circ} \mathrm{C}(1.5 \mathrm{~min}) \rightarrow 12^{\circ} \mathrm{C} / \mathrm{min} \rightarrow 300^{\circ} \mathrm{C}(10 \mathrm{~min})$ \\
TDS & $20^{\circ} \mathrm{C}(5 \mathrm{~min}) \rightarrow 60^{\circ} \mathrm{C} / \mathrm{min} \rightarrow 280^{\circ} \mathrm{C}(10 \mathrm{~min})$ \\
\hline
\end{tabular}

the gas emissions from the specimen under room-temperature conditions, the sample is removed from the microchamber and heated at a high temperature. The SVOC constituents adsorbed to the interior of the microchamber are collected, and the emission rate is determined by summing the two [16].

2.2. Recovery of the Microchamber. Assuming that the SVOCs emitted from the material will adsorb to the microchamber walls, the recovery rate was calculated using a reference standard SVOC substance. A predetermined amount of the reference SVOC material was directly added to Tenax TA. In total, $2 \mu \mathrm{L}$ of the reference SVOC solution was injected into the microchamber using a syringe. Then, thermal desorption was performed immediately. From the amount of SVOC collected, it was confirmed that the recovery rate was at least $90 \%$. Tables 1 and 2 list the measurement conditions of the thermal desorption test chamber system and the analytical conditions of the gas chromatography/ mass spectrometry thermal desorption system (GC/MS-TDS), respectively.

2.3. Measurements. Table 3 lists the test cases. In case 1, PVC flooring was used as the specimen (this flooring has been reported to emit DEHP, which is an SVOC). The flooring specimen was placed inside a desiccator and cured. After one day of curing, it was removed. The air supplied to the desiccator had a temperature of $28^{\circ} \mathrm{C} \pm 1^{\circ} \mathrm{C}$ and a relative humidity $(\mathrm{RH})$ of $50 \% \pm 5 \%$. PVC flooring was placed inside 
TABle 3: A list of test cases (air exchange rate $=1.5 \mathrm{~h}^{-1}$ ).

\begin{tabular}{lcccc}
\hline Case & Temperature $\left({ }^{\circ} \mathrm{C}\right)$ & Relative humidity $(\%)$ & Airborne particles & SVOC adsorption area \\
\hline 1 & 28 & 50 & - & Inner wall of the chamber \\
2 & 40 & 50 & - & Inner wall of the chamber \\
3 & 28 & 40 & - & Inner wall of the chamber \\
4 & 28 & 70 & Quartz wool: $170 \mathrm{mg}$ & Inner wall of the chamber \\
5 & 28 & 50 & Quartz wool: $340 \mathrm{mg}$ & Inner wall of the chamber + quartz wool \\
6 & 28 & 50 &
\end{tabular}

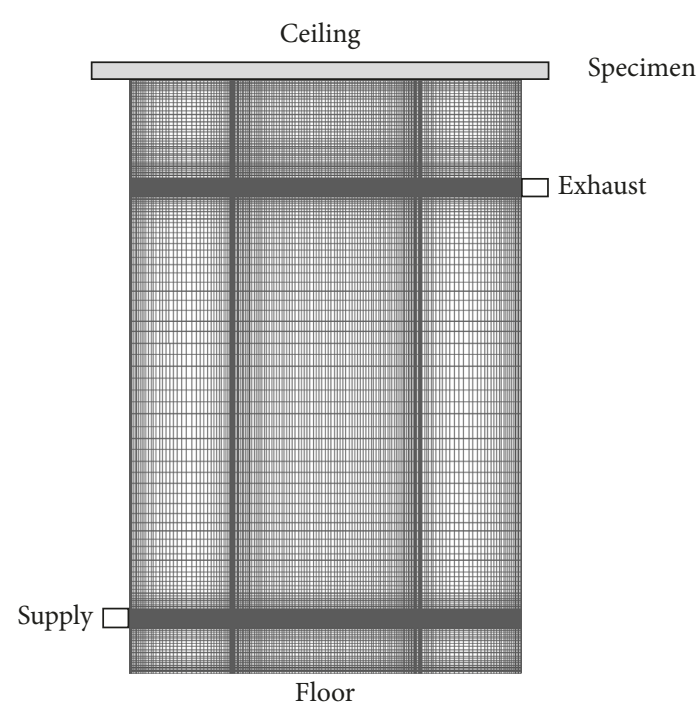

(a)

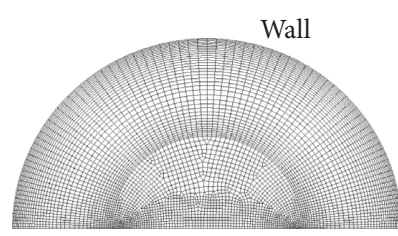

Symmetrical

(b)

FIGURE 3: Schematic of the analytical mesh: (a) vertical cross section (symmetrical) and (b) horizontal cross section.

the microchamber, and the test was conducted under the following conditions: temperature $=28^{\circ} \mathrm{C}, \mathrm{RH}=50 \%$, and air exchange rate $=0.5 \mathrm{~h}^{-1}$. The sample was a $115 \mathrm{~mm}$ diameter circle of flooring cut from the center of a roll of flooring (as shown in Figure 1, the emission area had a diameter of $82 \mathrm{~mm}$ due to the seal).

To ensure the reproducibility of the volume of chemicals emitted from the flooring specimen, the test performed in case 1 was repeated three times under the same conditions. The temperature inside the chamber was set to $28^{\circ} \mathrm{C}$ and $40^{\circ} \mathrm{C}$, and the dependence of the SVOC emission rate on the temperature was investigated.

The temperature in the high-temperature condition was set to $40^{\circ} \mathrm{C}$ considering the rise in the surface temperature of building materials placed in a location with good exposure to sunlight and the rise in the temperature of the surface of consumer electronics when running. The $\mathrm{RH}$ was set to 40,50 , and $70 \%$, and the influence of the changes in the $\mathrm{RH}$ on the SVOC emission rate was confirmed. The RH was set to $40 \%$ and 70\% because Japan's Act on Maintenance of Sanitation in Buildings sets the environmental standard for $\mathrm{RH}$ in offices between $40 \%$ and $70 \%$. Additionally, quartz wool was placed inside the microchamber, and the authors investigated the influence of the changes in the adsorption area due to the presence or absence of airborne particles. This wool was heated and cleaned before the experiment. As with the measurement of the recovery rate in the microchamber, we calculated the DEHP collection rate in the microchamber for cleaned quartz wool and confirmed a recovery rate of at least $90 \%$. To confirm that the SVOC emission rate was in a steady state, the emissions were sampled five times in case $1(0.5,3$, 12,24 , and $48 \mathrm{~h}$ after the experiment began) and three times in case $2(0.5,3$, and $24 \mathrm{~h}$ after the experiment began). In the other cases, the emissions were sampled 0.5 and $24 \mathrm{~h}$ after the experiment began, and the rate of SVOC emissions from the flooring specimen over time was investigated.

2.4. Numerical Method. Figure 3 shows a schematic of the analytical mesh. Tables 4 and 5 list the CFD analysis cases and conditions, respectively. The inlet boundary conditions were set as follows: air exchange rate $=1.5 \mathrm{~h}^{-1}$ $\left(U_{\text {in }}=2.1 \times 10^{-2} \mathrm{~m} / \mathrm{s}\right), 0.8 \mathrm{~h}^{-1}\left(U_{\text {in }}=3.9 \times 10^{-2} \mathrm{~m} / \mathrm{s}\right)$, and $4.0 \mathrm{~h}^{-1}$ $\left(U_{\text {in }}=5.2 \times 10^{-2} \mathrm{~m} / \mathrm{s}\right)$. Additionally, the air age and the coefficient of the air change performance $\eta$ in the microchamber were investigated [23]. The air age is defined as the length of time $t$ during which a specific amount of outdoor air has been in a building, zone, or space, and the coefficient of the air change performance is defined as an air distribution system's ability to deliver ventilation air to a building, zone, or space [24]. A three-dimensional analysis was performed based on a flow field of the low-Reynolds (Re)-type $k-\varepsilon$ model (Abe-Nagano model) [25]. Given the symmetry of the interior of the microchamber, only half of the area was subjected to analysis.

After analyzing the flow field, the surface gas-phase concentration of DEHP was set in the specimen position and the diffusion field was analyzed. Table 5 lists the DEHP surface gas-phase concentration $\left(C_{0}\right)$ and air diffusion coefficient $\left(D_{a}\right)$ values $[26,27]$. When determining the amount of DEHP emitted from the flooring specimen, it should be set as an internal diffusion-controlled building material; however, for computational convenience, this study's model is set as an evaporation-controlled building material. The concentration of the air flowing into the microchamber via 
TABLe 4: A list of computational fluid dynamics (CFD) analysis cases (temperature $=28^{\circ} \mathrm{C}$ ).

\begin{tabular}{lccc}
\hline Case & Air exchange rate $\left(\mathrm{h}^{-1}\right)$ & $U_{\text {in }}(\mathrm{m} / \mathrm{s})$ & Mass transfer coefficient* $(\mathrm{m} / \mathrm{h})$ \\
\hline 7 & 0.8 & $2.1 \times 10^{-2}$ & 0.9 \\
8 & 1.5 & $3.9 \times 10^{-2}$ & 3.5 \\
9 & 4.0 & $5.2 \times 10^{-2}$ & 7.7 \\
\hline
\end{tabular}

*The mass transfer coefficients in cases 7-9 are converted to water vapor. These values are calculated via CFD analysis [20].

TABLe 5: A list of CFD analysis conditions.

\begin{tabular}{|c|c|}
\hline Mesh divisions & Approximately 890,000 \\
\hline Turbulence model & Low-Reynolds (Re)-type $k-\varepsilon$ model (Abe-Nagano model) \\
\hline Difference scheme & First-order windward \\
\hline Supply boundary & $\begin{array}{c}U_{\text {in }}=2.1 \times 10^{-2} \mathrm{~m} / \mathrm{s}(\text { case } 7), 3.9 \times 10^{-2} \mathrm{~m} / \mathrm{s}(\text { case } 8), \text { and } 5.2 \times 10^{-2} \mathrm{~m} / \mathrm{s}(\text { case } 9) \\
L_{\text {in }}=3.0 \times 10^{-3} \mathrm{~m}, k=3 / 2\left(U_{\text {in }} \times 0.015\right)^{2}, \text { and } L=1 / 7 \cdot L_{\text {in }} \varepsilon=C_{u} \cdot k^{3 / 2} / L\end{array}$ \\
\hline Exhaust boundary & $U_{\text {out }}:$ via mass conservation; $k_{\text {out }}, \varepsilon_{\text {out }}:$ free slip \\
\hline
\end{tabular}

DEHP surface gas-phase concentration at $28^{\circ} \mathrm{C}\left(C_{s}\right)=298.3 \mu \mathrm{g} / \mathrm{m}^{3}$; DEHP air diffusion coefficient at $28^{\circ} \mathrm{C}\left(D_{a}\right)=7.1 \times 10^{-7} \mathrm{~m}^{2} / \mathrm{s}$.

TABLE 6: Test results (air exchange rate $=1.5 \mathrm{~h}^{-1}$ ).

\begin{tabular}{|c|c|c|c|c|c|c|c|c|}
\hline \multirow[b]{2}{*}{ Case } & \multirow[b]{2}{*}{$\begin{array}{c}\text { Temperature } \\
\left({ }^{\circ} \mathrm{C}\right)\end{array}$} & \multirow{2}{*}{$\begin{array}{l}\text { Relative } \\
\text { humidity } \\
(\%)\end{array}$} & \multirow[b]{2}{*}{$\begin{array}{c}\text { Airborne } \\
\text { particles }\end{array}$} & \multirow[b]{2}{*}{ SVOC adsorption area } & \multicolumn{2}{|c|}{ DEHP collection volume (ng) } & \multicolumn{2}{|c|}{ DEHP emission rate $\left(\mu \mathrm{g} / \mathrm{m}^{2} \mathrm{~h}\right)$} \\
\hline & & & & & $\begin{array}{l}0.5 \mathrm{~h} \text { after the } \\
\text { exp. began }\end{array}$ & $\begin{array}{l}24 \mathrm{~h} \text { after the } \\
\text { exp. began }\end{array}$ & $\begin{array}{l}0.5 \mathrm{~h} \text { after the } \\
\text { exp. began }\end{array}$ & $\begin{array}{c}24 \mathrm{~h} \text { after the } \\
\text { exp. began }\end{array}$ \\
\hline 1 & 28 & 50 & - & $\begin{array}{l}\text { Inner wall of the } \\
\text { chamber }\end{array}$ & 131.9 & 1686.4 & 49.8 & 13.3 \\
\hline 2 & 40 & 50 & - & $\begin{array}{c}\text { Inner wall of the } \\
\text { chamber }\end{array}$ & 184.0 & 5365.0 & 69.4 & 42.2 \\
\hline 3 & 28 & 40 & - & $\begin{array}{c}\text { Inner wall of the } \\
\text { chamber }\end{array}$ & 100.0 & 1293.6 & 37.7 & 10.2 \\
\hline 4 & 28 & 70 & - & $\begin{array}{c}\text { Inner wall of the } \\
\text { chamber }\end{array}$ & 240.0 & 1172.5 & 90.6 & 9.2 \\
\hline 5 & 28 & 50 & $\begin{array}{l}\text { Quartz } \\
\text { wool: } \\
170 \mathrm{mg}\end{array}$ & $\begin{array}{l}\text { Inner wall of the } \\
\text { chamber + quartz wool }\end{array}$ & 335.9 & 2733.0 & 126.8 & 20.6 \\
\hline 6 & 28 & 50 & $\begin{array}{l}\text { Quartz } \\
\text { wool: } \\
340 \mathrm{mg}\end{array}$ & $\begin{array}{c}\text { Inner wall of the } \\
\text { chamber + quartz wool }\end{array}$ & 671.8 & 3723.0 & 253.5 & 29.1 \\
\hline
\end{tabular}

the air inlet was set to zero, and the constant concentration was calculated under isothermal conditions $\left(28^{\circ} \mathrm{C}\right)$.

\section{Results}

Table 6 and Figures 4-6 show the measurements of the rate at which DEHP was emitted from the flooring specimen due to influencing factors, including temperature, $\mathrm{RH}$, and airborne particles.

3.1. Relation between the DEHP Emission Rate and Temperature. In case $1,0.5 \mathrm{~h}$ after the initiation of the experiment, the rate at which DEHP was emitted from the flooring specimen was $49.8 \mu \mathrm{g} / \mathrm{m}^{2} \mathrm{~h}$. However, over time, the DEHP emission rate decreased. Approximately $10 \mathrm{~h}$ after the initiation of the experiment, the DEHP emission rate reached a steady state. At this point, the DEHP emission rate was $13.3 \mu \mathrm{g} / \mathrm{m}^{2} \mathrm{~h}$ (Table 6 and Figure 4 ). In case 2, the temperature was set to $40^{\circ} \mathrm{C}$ considering the rise in the temperature of the surface of the flooring specimen because of the exposure to sunlight or the like. In this case, $24 \mathrm{~h}$ after the initiation of the experiment, the rate at which DEHP was emitted from the flooring specimen was $42.2 \mu \mathrm{g} / \mathrm{m}^{2} \mathrm{~h}$. As shown in Figure 4 , we confirmed that the emission rate of DEHP was dependent on the temperature.

The DEHP emission rate determined $24 \mathrm{~h}$ after the initiation of the experiment is an average value over three measurements; the relative standard deviation (RSD) is $4 \%$.

3.2. Relation between DEHP Emission Rate and RH. In case 3 , the RH was set to $40 \% .0 .5$ and $24 \mathrm{~h}$ after the start of the experiment, the rates of DEHP emissions from the flooring specimen were 37.7 and $10.2 \mu \mathrm{g} / \mathrm{m}^{2} \mathrm{~h}$, respectively. Thus, the DEHP emission rates obtained in this case were not considerably different from those obtained in case 1 wherein the $\mathrm{RH}$ was set to $50 \%$. Furthermore, in case 4 , the relative humidity was set to $70 \%$, and $24 \mathrm{~h}$ after the initiation of the experiment, the rate at which DEHP was emitted from the flooring specimen was $9.2 \mu \mathrm{g} / \mathrm{m}^{2} \cdot \mathrm{h}$. Katsumata et al. reported that there were almost no differences in the DEHP emission rates, regardless of whether the air supplied to the microchamber was humidified or dry [16]. The present 


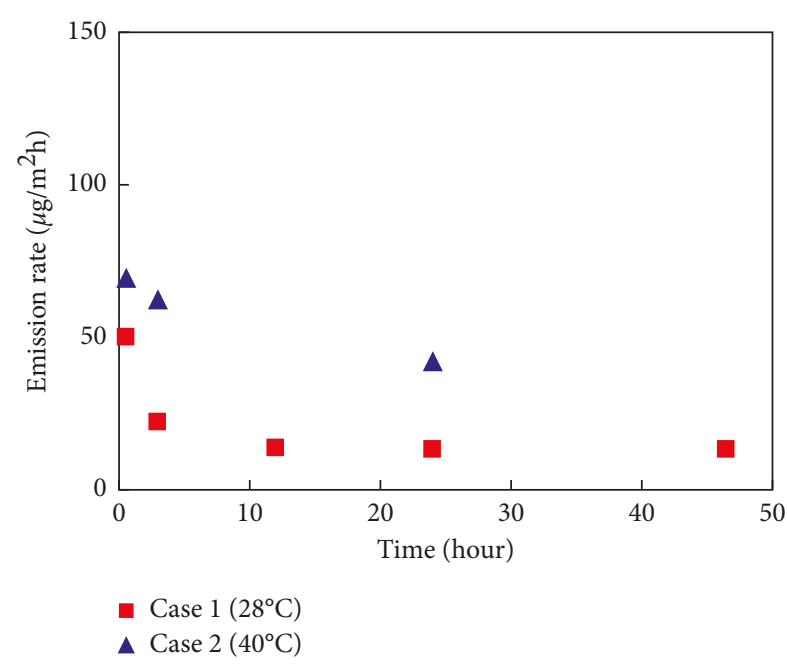

FIGURE 4: A plot of emission rate versus time showing the emission of di-2-ethylhexyl phthalate (DEHP) from the flooring specimen with regard to the temperature.

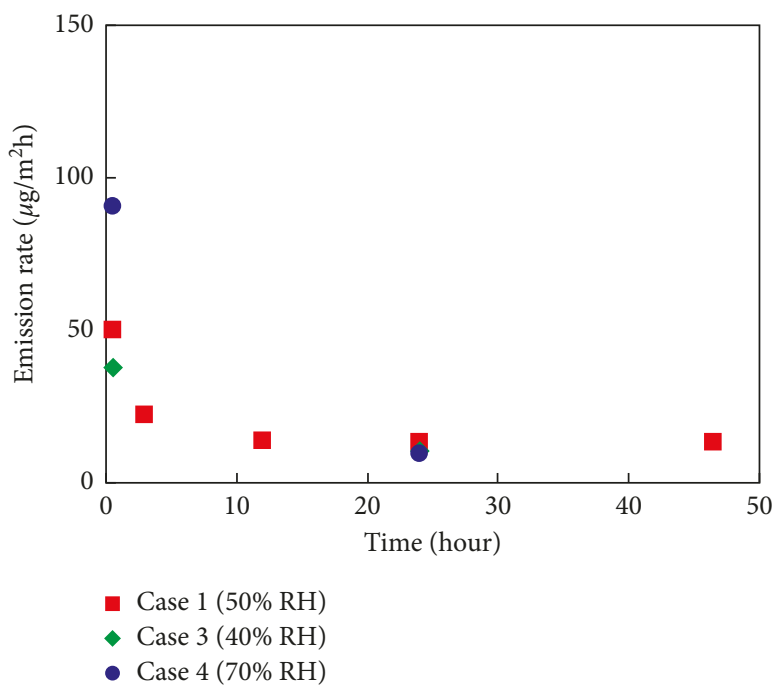

FIGURE 5: A plot of emission rate versus time showing the emission of DEHP from the flooring specimen with regard to relative humidity $(\mathrm{RH})$.

experiment also confirms that a certain amount of time after the initiation of the experiment, the DEHP emission rate was not considerably influenced by the $\mathrm{RH}$ in the range $40 \%-70 \%$ (Figure 5).

\subsection{Relation between DEHP Emission Rate and Airborne} Particles. In case 5, quartz wool (170 mg) was placed in the microchamber as airborne particles. In case $6,340 \mathrm{mg}$ of quartz wool was used. Table 6 and Figure 6 show the experimental results. In case 5 , when $170 \mathrm{mg}$ of quartz wool was placed in the microchamber, 2,733.0 ng of DEHP was collected and the DEHP emission rate was $20.6 \mu \mathrm{g} / \mathrm{m}^{2} \mathrm{~h}$. Thus, the collected volume and emission rate were considerably greater than those in case 1 wherein no quartz wool was used

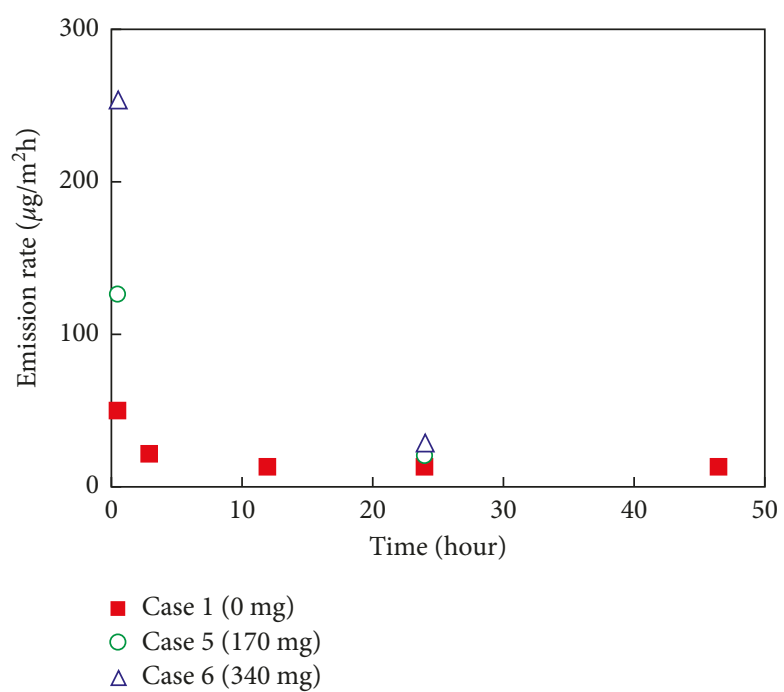

FIgURE 6: A plot of emission rate versus time showing the emission of DEHP from the flooring specimen with regard to airborne particles.

(amount of DEHP collected $=1,686.4 \mathrm{ng}$; DEHP emission rate $=20.6 \mu \mathrm{g} / \mathrm{m}^{2} \mathrm{~h}$ ). In case 6 wherein $340 \mathrm{mg}$ of quartz wool was used (amount of DEHP collected $=3,723.0 \mathrm{ng}$; DEHP emission rate $=29.1 \mu \mathrm{g} / \mathrm{m}^{2} \mathrm{~h}$ ), the DEHP collection volume and emission rate were higher than those in case 5 . This indicates that increasing the volume of airborne particles increases the area available for DEHP adsorption. It is thus believed that the SVOC emission rates are considerably affected by the adsorption surface area (the surface area of the interior of the microchamber and the surface area of the airborne particles).

3.4. Prediction Results for the Flow Field within the Microchamber. Table 7 and Figure 7 show the results of a CFD analysis of the airflow distribution, average air age, coefficient of the air change performance, and other factors for each case.

In case 7 , the inlet speed of the microchamber supply was set to $2.1 \times 10^{-2} \mathrm{~m} / \mathrm{s}$ and the air exchange rate was set to $0.8 \mathrm{~h}^{-1}$. In this case, the average airflow in the microchamber was $4.7 \times 10^{-5} \mathrm{~m} / \mathrm{s}$ and the airflow near the specimen was $3.5 \times 10^{-5} \mathrm{~m} / \mathrm{s}$. In cases 8 and 9 , the air exchange rate was set to $1.5 \mathrm{~h}^{-1}$. In the experiments performed in these cases, the increase in the air exchange rate exhibited an increase in the average airflow in the microchamber (Table 7). In cases 7 (air exchange rate $=0.8 \mathrm{~h}^{-1}$ ) and $8\left(\right.$ air exchange rate $\left.=1.5 \mathrm{~h}^{-1}\right)$, the air flows straight up from the center of the microchamber, whereas in case 9 (air exchange rate $=4.0 \mathrm{~h}^{-1}$ ), there is a large S-shaped airflow vector distribution. In cases 7 and 8 , there is almost no circulating flow in the microchamber area as a whole. In contrast, in case 9, the high air supply rate causes the flow to collide with the front of the air inlet.

Figures $7(a)-7$ (c) show the air age [23] in the microchamber. These values are the average of local air ages at all points in the microchamber. Here, the local average air age is the amount of time required by air to move from the air inlet to an arbitrary point inside the microchamber. 
TABLE 7: CFD analysis results (air exchange rate $=1.5 \mathrm{~h}^{-1}$ ).

\begin{tabular}{lccc}
\hline Case & 7 & 8 & 9 \\
\hline Air exchange rate $\left(\mathrm{h}^{-1}\right)$ & 0.8 & 1.5 & 4.0 \\
$U_{\text {in }}(\mathrm{m} / \mathrm{s})$ & $2.1 \times 10^{-2}$ & $3.9 \times 10^{-2}$ & $5.2 \times 10^{-2}$ \\
Average airflow in the microchamber $(\mathrm{m} / \mathrm{s})$ & $4.7 \times 10^{-5}$ & $3.9 \times 10^{-5}$ & $1.5 \times 10^{-4}$ \\
Airflow near the specimen $(\mathrm{m} / \mathrm{s})$ & $3.5 \times 10^{-5}$ & $5.0 \times 10^{-5}$ & $3.0 \times 10^{-5}$ \\
Mass transfer coefficient $(\mathrm{m} / \mathrm{h})$ & 0.9 & 3.5 & 7.7 \\
Average age of air in the microchamber & 0.79 & 0.87 & 0.8 \\
Coefficient of air change performance & 1.6 & 0.78 \\
\hline
\end{tabular}

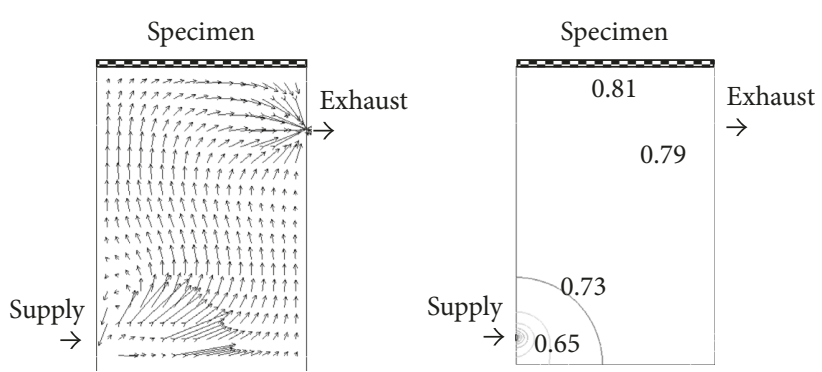

(a)

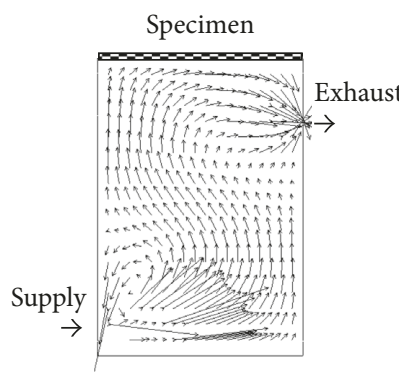

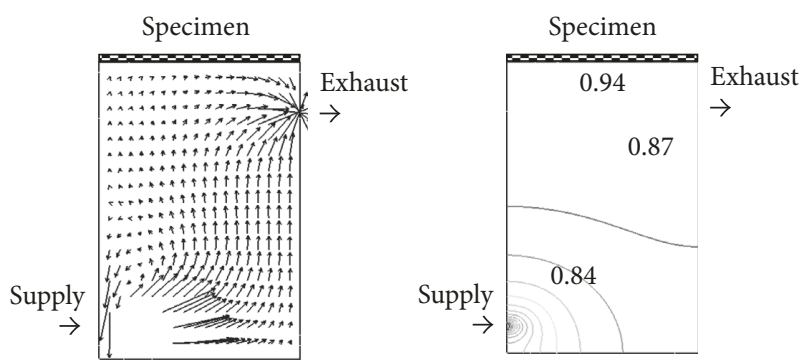

(b)

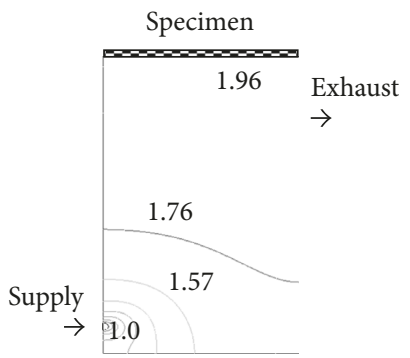

(c)

Figure 7: Distribution of airflow vectors and air ages: (a) air change rate of 0.8 times/h, (b) air change rate of 1.5 times/h, and (c) air change rate of 4.0 times/h.

In cases $7-9$, the average air age values in the microchamber were $0.79,0.87$, and 1.78 , respectively. Thus, as the air exchange rate increased, the average air age tended to increase (Table 7). In particular, the air age values near the top of the microchamber (where the specimen was placed) were 0.81 in case $7,0.94$ in case 8 , and 1.96 in case 9. Thus, fresh air required the maximum amount of time to travel from the microchamber's inlet to the top of the microchamber in case 9 wherein the air exchange rate was $4.0 \mathrm{~h}^{-1}$. This may be because the high air supply rate in case 9 caused a circulating flow in the microchamber, as described above.

The coefficient of the air change performance corresponds to the air change performance in the microchamber. For example, if the air in the microchamber is in a completely mixed state, the coefficient of the air change performance will be 1 [23].

In case 7 , the coefficient of the air change performance was 1.6. As shown in Figure 7(a), almost no stagnant areas or circulating flows were formed in the microchamber in this case. In case 8 , the coefficient of the air change performance was 0.8. In this case, there was a slight stagnant area in the microchamber; however, the coefficient of the air change performance was close to 0.9 , which is the stipulated coefficient of the air change performance for a small chamber method in JIS A 1901 [23]. In case 9, the coefficient of the air change performance was 0.1 . Thus, despite the high air exchange rate, there apparently was a high formation of stagnant areas and circulating flows in the microchamber (Figure $7(\mathrm{c})$ ).

\section{Discussion}

As shown in Figures 4-6, the rate at which DEHP was emitted from the flooring specimen was high at the beginning of the experiments $(0.5 \mathrm{~h}$ after the initiation of the experiment); however it gradually declined over time. $24 \mathrm{~h}$ after the initiation of the experiment, the emission rate stabilized. When experiments are conducted to measure SVOC emission rates using a microchamber, it is preferable to calculate the rates in the steady state that is reached $24 \mathrm{~h}$ after the initiation of the experiment.

Figure 8 shows a comparison of DEHP emission rates in the presence of factors influencing this rate. It was confirmed that the rate at which DEHP is emitted from the flooring specimen considerably depends on the temperature. An increase in the temperature excites the thermal motion of the 


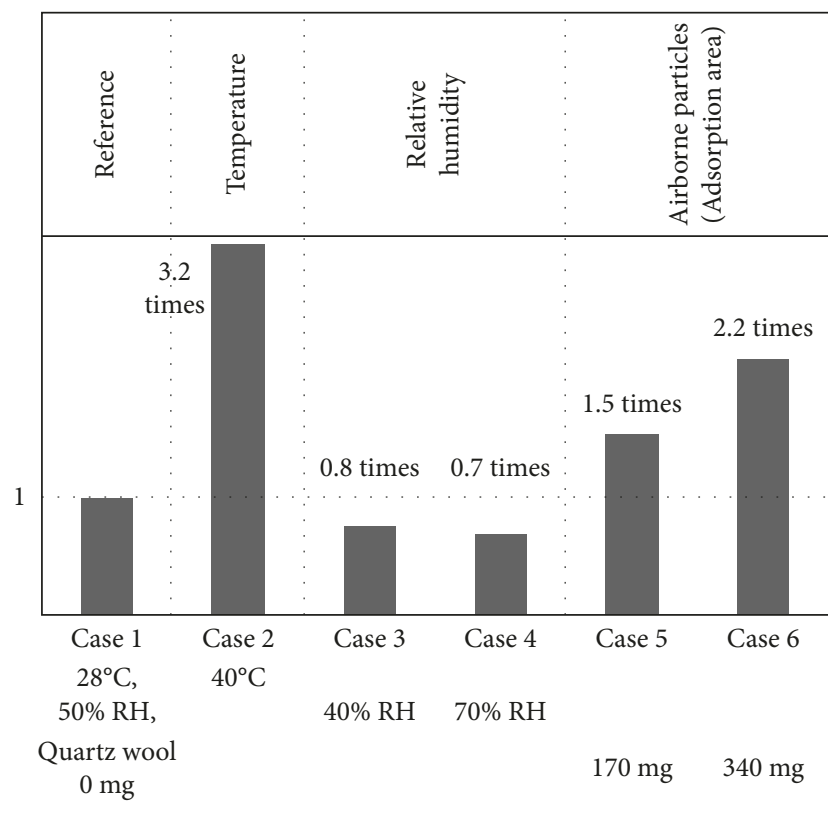

FIGURE 8: Comparison of DEHP emission rates in the presence of factors influencing this rate.

molecular chains, which has a significant impact on the emission of chemicals. The DEHP and resin chains contained in the flooring specimen are bound via intermolecular forces. The increases in temperature may gradually free the DEHP molecules from the resin, thereby increasing the DEHP emission rate. In contrast, there were no significant changes in the DEHP emission rates when the RH was changed. This may be because DEHP, which is hydrophobic, is not considerably influenced by humidity.

It was found that the increase in the adsorption area in the presence of airborne particles, that is, the increase in the surface area available for DEHP adsorption, is directly correlated to the increase in the DEHP emission rate. However, the increase in the DEHP emission rate was not directly proportional to the increase in the airborne particle volume because of the relation between the location of the emission source in the microchamber and the flow field. Figure 9 shows the results of an analysis performed under the conditions same as those in case 1 but with the surface concentration of the flooring specimen set to $298.3 \mu \mathrm{g} / \mathrm{m}^{3}$. In this experiment, the DEHP emissions from the specimen were diffused; however, a concentration boundary layer was formed at the top of the microchamber wall. Additionally, the DEHP emissions were considerably influenced by the flow field (Figure 7(b)), possibly because DEHP is only adsorbed to a considerably small part of the microchamber walls at the top of the chamber (Figure 9). Although the extreme conditions must be considered (e.g., the walls' boundary conditions having unlimited adsorption capacity), DEHP was preferentially adsorbed to a part of the microchamber's interior surface that was near the emission source. Additionally, in cases wherein quartz wool was used as airborne particles, DEHP only adsorbed to a portion at the top of the quartz wool (in cases involving the use of 170 and $340 \mathrm{mg}$ of quartz wool).

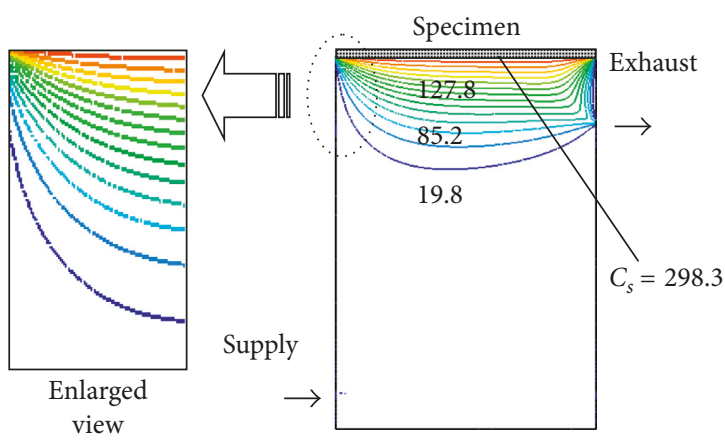

FIgURE 9: DEHP concentration distribution: air change rate $=1.5$ times $/ \mathrm{h}$.

When the air exchange rate in the microchamber increased, the water vapor-equivalent mass transfer coefficient of the specimen surface rose. Despite this fact, stagnant areas and circulating flows also formed inside the microchamber, resulting in a far worse air change efficiency. Conversely, when a low air exchange rate was set, the air change efficiency in the microchamber was excellent; however, the mass transfer coefficient decreased to less than $1 \mathrm{~m} / \mathrm{h}$. The experimental findings suggest that supplying ventilation air (or helium) with an air exchange rate of $\sim 1.5 \mathrm{~h}^{-1}$ is appropriate for the microchamber method.

\section{Conclusions}

Herein, we investigated the effects of temperature, RH, airborne particles, and air change properties on the emission rate of DEHP-an SVOC-using the microchamber method. Our results are summarized as follows:

(1) This research confirmed that the DEHP emission rate considerably depends on the temperature set for the experiment. When the microchamber method is utilized as the standard testing method, it is essential to set the temperature to a constant level to ensure that the performance of the experimental sample is evaluated uniformly.

(2) Although the DEHP emission rate was not shown to depend on humidity in this research, there is a need to investigate DEHP emission rates in low-humidity environments below $40 \% \mathrm{RH}$.

(3) Depending on the volume of airborne particles, we confirmed that placing quartz wool in the microchamber as airborne particles caused a considerable change in the DEHP emission rate.

(4) We set three patterns of air exchange rates and investigated the airflow characteristics in the microchamber for each pattern using the air change efficiency indicators of air age and coefficient of air change performance. With the microchamber method, it is preferable to conduct experiments with an air exchange rate of $\sim 1.5 \mathrm{~h}^{-1}$.

(5) It was shown that the emissions were greatly influenced by the flow field in the microchamber and 
that nearly all SVOCs emitted by the specimen were only adsorbed to the inner walls at the top of the microchamber.

(6) The changes in the DEHP emission rates in lowtemperature and low-humidity environments must be investigated. In the future, we plan to investigate the relation between emission rate and the factors influencing this rate for other types of SVOCs. We also plan to conduct experiments adapted to CFD analysis and verify the degree of adaptability to this type of analysis.

\section{Conflicts of Interest}

The authors declare that they have no conflicts of interest.

\section{Acknowledgments}

This work was supported by a National Research Foundation of Korea (NRF) grant funded by the Korean Government (NRF-2015R1C1A1A01052784).

\section{References}

[1] C. G. Bornehag, J. Sundell, C. J. Weschler et al., "The association between asthma and allergic symptoms in children and phthalates in house dust: a nested case control study," Environmental Health Perspectives, vol. 112, no. 14, pp. 1393-1397, 2004.

[2] T. Salthammer and M. Wensing, "Flame retardants in the indoor environment part IV: classification of experimental data from house dust, indoor air and chamber tests," in Proceedings of the 9th International Conference on Indoor Air Quality and Climate-Indoor Air 2002, vol. 2, pp. 213-218, Monterey, CA, USA, July 2002.

[3] P. A. Clausen, V. Hansen, L. Gunnarsen, A. Afshari, and P. Wolkoff, "Emission of di-2-ethylhexyl phthalate from PVC flooring into air and uptake in dust: emission and sorption experiments in FLEC and CLIMPAQ," Environmental Science \& Technology, vol. 38, no. 9, pp. 2531-2537, 2004.

[4] WHO, Indoor Air Quality: Organic Pollutants, EURO Reports and Studies, vol. 111, World Health Organization, Copenhagen, Denmark, 1987.

[5] J. J. Adibi, F. P. Perera, W. Jedrychowski et al., "Prenatal exposures to phthalates among women in New York City and Krakow, Poland," Environmental Health Perspectives, vol. 111, no. 14, pp. 1719-1722, 2003.

[6] C. J. Weschler, "Indoor/outdoor connections exemplified by processes that depend on an organic compound's saturation vapor pressure," Atmospheric Environment, vol. 37, no. 39-40, pp. 5455-5465, 2003.

[7] C. G. Bornehag, J. Sundell, and T. Sigsgaard, "Dampness in buildings and health (DBH): report from an on-going epidemiological investigation on the association between indoor environmental factors and health effects among children in Sweden," Indoor Air, vol. 14, no. 7, pp. 59-66, 2004.

[8] J. Pei, Y. Yin, J. Cao, Y. Sun, J. Liu, and Y. Zhang, "Time dependence of characteristic parameter for semi-volatile organic compounds (SVOCs) emitted from indoor materials," Building and Environment, vol. 125, no. 15, pp. 339-347, 2017.

[9] S. T. Larsen, R. M. Lund, G. D. Nielsen, P. Thygesen, and O. M. Poulsen, "Di-(2-ethylhexyl) phthalate possesses an adjuvant effect in a subcutaneous injection model with BALB/c mice," Toxicology Letters, vol. 125, no. 1-3, pp. 11-18, 2001.

[10] Y. Liang and Y. Xu, "The influence of surface sorption and air flow rate on phthalate emissions from vinyl flooring: measurement and modeling," Atmospheric Environment, vol. 103, pp. 147-155, 2015.

[11] M. Noguchi and A. Yamasaki, "Passive flux sampler measurements of emission rates of phthalates from poly(vinyl chloride) sheets," Building and Environment, vol. 100, pp. 197-202, 2016.

[12] Y. Sun, Q. Zhang, J. Hou, P. Wang, and J. Sundell, "Exposure of phthalates in residential buildings and its health effects," Procedia Engineering, vol. 205, pp. 1901-1904, 2017.

[13] P. A. Clausen, Y. Xu, V. Kofoed-Sørensen, J. C. Little, and P. Wolkoff, "The influence of humidity on the emission of di(2-ethylhexyl) phthalate (DEHP) from vinyl flooring in the emission cell "FLEC"," Atmospheric Environment, vol. 41, no. 15, pp. 3217-3224, 2007.

[14] N.-Y. Hsu, Y.-C. Liu, C.-W. Lee, C.-C. Lee, and H.-J. Su, "Higher moisture content is associated with greater emissions of DEHP from PVC wallpaper," Environmental Research, vol. 152, pp. 1-6, 2017.

[15] T. Schripp, C. Fauck, and T. Salthammer, "Chamber studies on mass-transfer of di(2-ethylhexyl)phthalate (DEHP) and di-n-butylphthalate (DnBP) from emission sources into house dust," Atmospheric Environment, vol. 44, no. 24, pp. 28402845, 2010.

[16] H. Katsumata, S. Murakami, S. Kato, K. Hoshino, and Y. Ataka, "Measurement of semi-volatile organic compounds emitted from various types of indoor materials by thermal desorption test chamber method," Building and Environment, vol. 43, no. 3, pp. 378-383, 2008.

[17] Y.-F. Mao, Z. Li, Y.-L. He, and W.-Q. Tao, "CFD analysis of SVOC mass transfer in different chambers," International Journal of Heat and Mass Transfer, vol. 99, pp. 613-621, 2016.

[18] Y. Liang, O. Caillot, J. Zhang, J. Zhu, and Y. Xu, "Large-scale chamber investigation and simulation of phthalate emissions from vinyl flooring," Building and Environment, vol. 89, pp. 141-149, 2015.

[19] X. Liu, Z. Guo, and N. F. Roache, "Experimental method development for estimating solid-phase diffusion coefficients and material/air partition coefficients of SVOCs," Atmospheric Environment, vol. 89, pp. 76-84, 2014.

[20] Japanese Industrial Standards A 1904, Determination of the Emission of Semi Volatile Organic Compounds for Building Products-Micro Chamber Method, Japanese Standards Association, Tokyo, Japan, 2008.

[21] Y. Wu, S. S. Cox, Y. Xu et al., "A reference method for measuring emissions of SVOCs in small chambers," Building and Environment, vol. 95, pp. 126-132, 2016.

[22] Y. Li and J. Zhu, "Identification of sink spots in two thermal desorption GC/MS systems for the analysis of polycyclic aromatic hydrocarbons," Analytica Chimica Acta, vol. 961, pp. 67-73, 2017.

[23] Japanese Industrial Standards A 1901, Determination of the Emission of Volatile Organic Compounds and Aldehydes for Building Products-Small Chamber Method, Japanese Standards Association, Tokyo, Japan, 2003.

[24] Ashrae Handbook, Fundmentals, ASHRAE, Atlanta, GA, USA, 2017.

[25] K. Abe, T. Kondoh, and Y. Nagano, "A new turbulence model for predicting fluid flow and heat transfer in separating and reattaching flows-I. Flow field calculations," International 
Journal of Heat and Mass Transfer, vol. 37, no. 1, pp. 139-151, 1994.

[26] Y. Ataka, S. Kato, S. Murakami, Q. Zhu, K. Ito, and T. Yokota, "Study of effect of adsorptive building material on formaldehyde concentrations: development of measuring methods and modeling of adsorption phenomena," Indoor Air, vol. 14, no. 8, pp. 51-64, 2004

[27] The Society of Chemical Engineers, The Handbook of the Chemical Engineering Science, Maruzen Co., Ltd., Tokyo, Japan, 2001, in Japanese. 


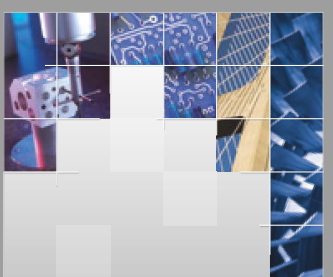

\section{Enfincering}
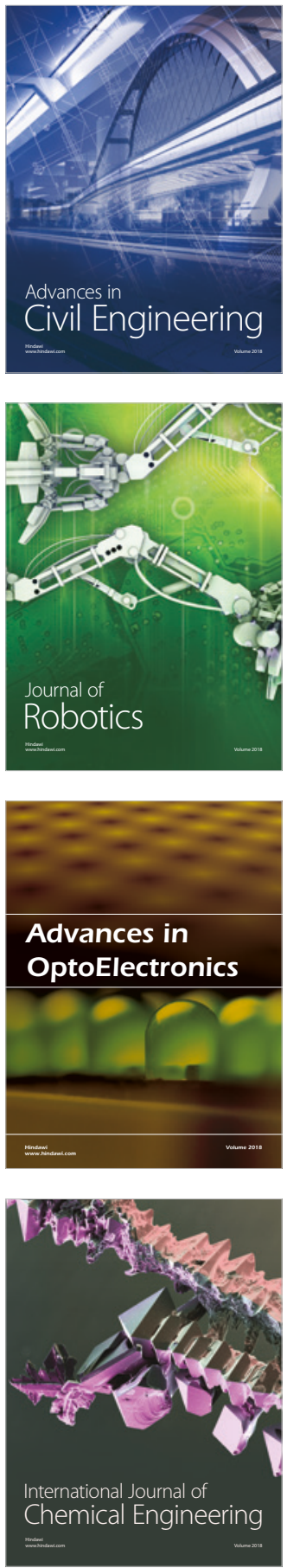

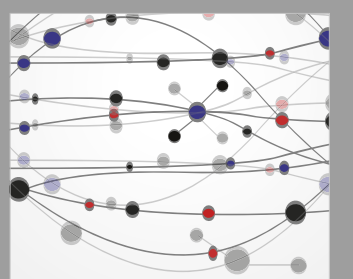

\section{Rotating \\ Machinery}

The Scientific World Journal

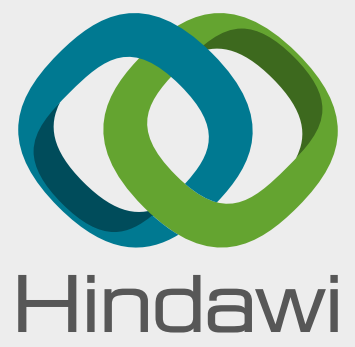

Submit your manuscripts at

www.hindawi.com
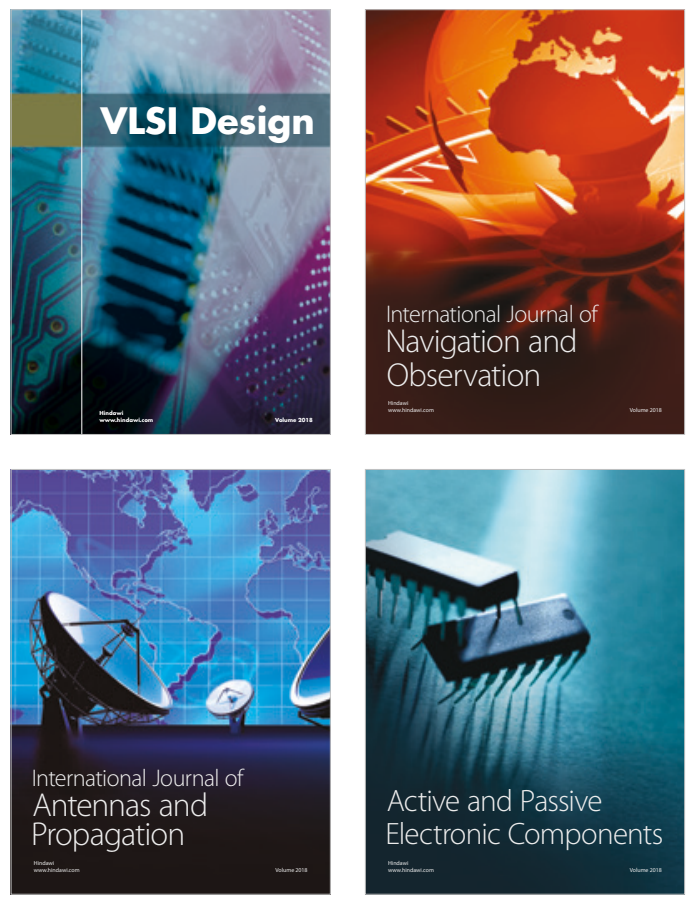
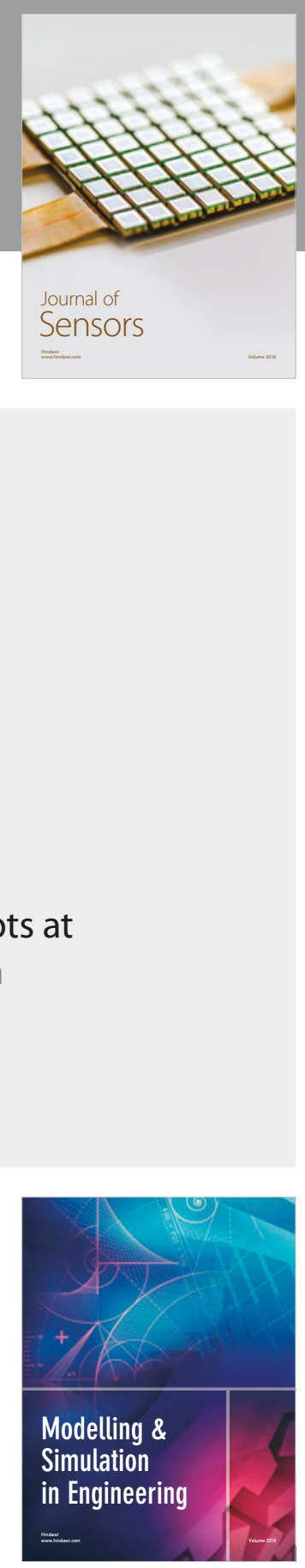

\section{Advances \\ Multimedia}
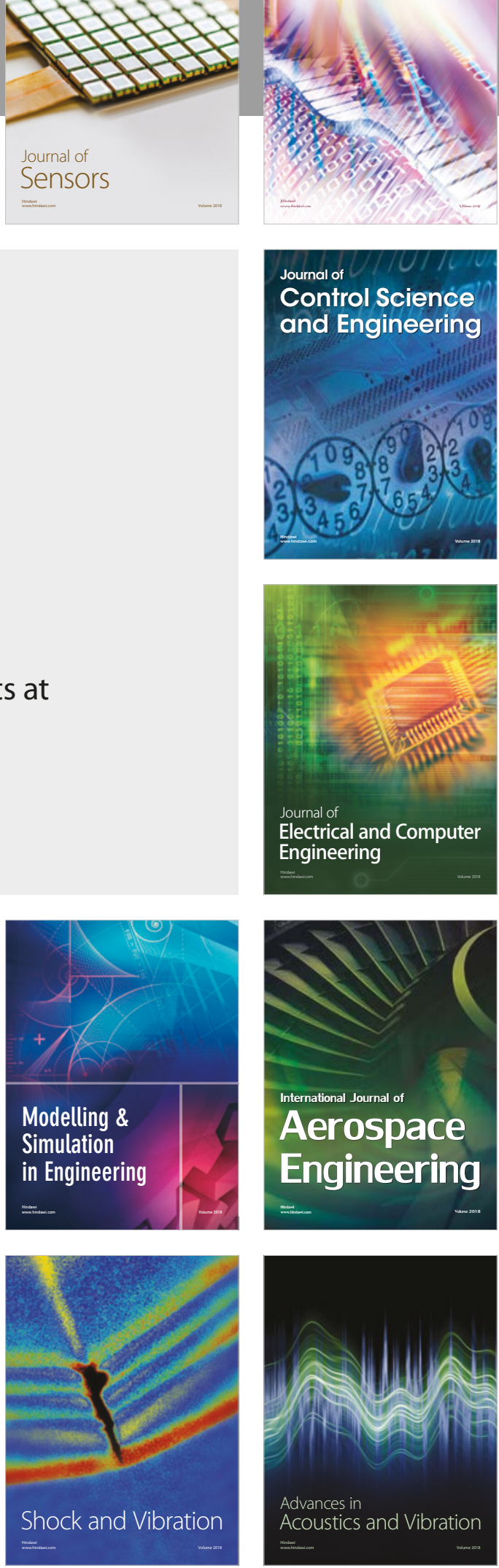